\title{
NEW ONLINE TRAINING PLATFORM LAUNCHED
}

The first online learning platform for revising for Situational Judgement Tests (SJT) has been launched. www.dentalSJT was made by dentist William Maguire and includes a free exclusive online guide for preparing for your exam and a list of for recommended reading topics.

William said: 'More practice can help reduce your anxiety about the exam and make you feel more prepared. Remember your UKCAT (now UCAT) or driving theory practice tests? Well this resource is just like that, only it focuses on your Situational Judgement Test.

'I sat multiple SJTs before obtaining Foundation Dental Training and Dental Core
Training jobs. As a final year student, this would have been welcome.'

You can purchase a question pack - either 30 ranking type questions or 30 best of 3 type questions for only $£ 10$ (66\% discount) if you use the coupon BDJ2020" during the checkout process. Visit www.dentalSJT.com.

\section{BRITISH DENTISTS} LAUNCH FREE COSMETIC DENTAL TIPS WEBSITE AND MAILING LIST

Kaizen Dental UK has launched a free website and mailing list to teach dentists cosmetic skills and tips in an easy to understand format.

The mailing list, launched on 2 July 2020, has already attracted over 700 members. Weekly tips are delivered by email every Thursday at $1 \mathrm{pm}$.

Co-Founder, Kris Vekaria, said: 'We tailor our content so that it can be understood by anybody, regardless of the stage they are at in their career.

'We include original diagrams and photographs to supplement the core topics we discuss.

'The tips are formatted to be 1-2 minute reads, so that they can be easily read and digested.'

For further information and to sign up visit www.kaizendental.co.uk

\section{Report published on returning to clinic}

The Dental Schools Council (DSC) has published a report which analyses the safety of returning students to dental clinical placements during the COVID-19 pandemic.

The report summarises the relevant literature on COVID-19 and suggests opportunities to rationalise and manage risk within dental clinical settings.

Summarising the risks associated with restarting clinical placements and proposing ways to minimise those risks is critical to reassuring students, staff, patients and the public of the safety of returning students to dental clinics. Plans to restart routine dental procedures, including those undertaken by students, will need to be tempered by an understanding of the practical difficulties arising from the presence in both clinical and associated non-clinical facilities of variable numbers of students, staff and patients, and the requirement for social distancing.

Clinical placements play an essential role in dental education and training. By treating patients, students gain hands-on experience of providing dental treatment and expand their knowledge of dental theory. Returning students to placements where it is safe to do so will help to future-proof the profession should further pandemics occur. It will also reduce the risk this pandemic poses to longer-term workforce planning by preventing delays to the registration of newly qualified dental care professionals.

To read the report visit: www.dentalschoolscouncil.ac.uk/ wp-content/uploads/2020/07/COVID-19-report-on-returning-tostudent-led-dental-clinical-treatments-v.1.1.pdf. 